\title{
STRATEGI DAKWAH PERSPEKTIF INFORMAL POPULER (Telaah Dakwah KH. A Shohibul Wafa Tajul Arifin)
}

\author{
Oleh: Irwan Misbach \\ Fakultas Dakwah dan Komunikasi \\ UIN Alauddin Makassar
}

\begin{abstract}
:
The problems faced by the ummah always differ both qualitatively and quantitatively. However, these people's problems need to be identified and sought for relevant and strategic solution solutions through da'wah strategy which includes systematic, smart, and professional method, approach, and technical preaching. Abah Anom as kyai or figure who has a strategic and central position in society and as self-educated. With his position, then he can provide Islamic religious knowledge to the pesantren community as a traditional educational institution which is a means to transfer knowledge to the community as an informal leader. Abah Anom's strategy of preaching emphasizes the method of dhikrullah (remembering Allah). It is based on the word of Allah swt, that the Qur'an can be a medicine.
\end{abstract}

\section{Keywords \\ Strategy, Da'wah, Informal}

\section{PENDAHULUAN}

Mendakwahkan Islam berarti memberikan jawaban terhadap berbagai permasalahan umat. Karenanya dakwah Islam selalu terpanggil untuk menyelesaikan berbagai permasalahan yang sedang dan akan dihadapi oleh umat manusia. Meskipun misi dakwah dari dulu sampai kini tetap pada mengajak umat manusia ke dalam sistem Islam, namun tantangan dakwah berupa problematika umat yang bermacam-macam senantiasa berubah dari waktu kewaktu.

Permasalahan yang dihadapi oleh umat selalu berbeda baik secara kualitatif maupun kuantitatif. Namun demikian, permasalahan-permasalahan umat ini perlu diidentifikasi dan dicari solusi pemecahan yang relevan dan strategis melalui strategi dakwah yang meliputi metode, pendekatan, dan teknis dakwah yang sistematis, smart, dan profesional.

Di tengah-tengah carut marut kehidupan dan kehancuran moral bangsa, KH. A. Shohibul Wafa Tajul Arifin ${ }^{1}$ atau yang dikenal dengan sebutan Abah Anom menawarkan sebuah solusi strategi dakwah dengan dzikir.Pesantrennya juga dikenal sebagai pusat pengobatan dan pembinaan para korban narkoba dan remaja nakal melalui metode agama, terutama metode zikir dan ibadah.

Abah Anom sebagai kyai atau tokoh yang mempunyai posisi strategis dan sentral dalam masyarakat dan sebagai diri terdidik. Dengan kedudukannya tersebut, maka beliau bisa memberikan pengetahuan agama Islam kepada masyarakat pesantren sebagai lembaga pendidikan tradisional yang merupakan sarana untuk mentransfer pengetahuan kepada 
masyarakat sebagai pemimpin informal. Dan beliau diyakini mempunyai otoritas yang sangat besar dan kharismatik di lingkungan sekitar dan para murid-muridnya.

\section{PEMBAHASAN}

\section{Biografi Abah Anom}

Abah Anom, lahir pada 11 Januari 1915, adalah putra kelima dari Syekh Abdullah Mubarok Ibn Nur Muhammad. Ibunya adalah Hajjah Juhriyah. Abah Anom memulai pendidikan formalnya di Vervolig Scool, Ciamis antara 1923-1928. Kemudian melanjutkan ke madrasah tsanawiyah (sekolah menengah) di Ciawi, Tasikmalaya. Sejak usia 15 tahun, yakni 1930, Abah Anom mulai secara khusus mendalami ilmu-ilmu agama.

Pada 1935-1937 Abah Anom berguru kepada Ajengan Atjeng Mumu. Di pesantren inilah Abah Anom mendapat ilmu tentang manajemen pesantren, ilmu berburu dan ilmu-ilmu sosial lainnya. Pada 1938 Abah Anom pergi ke Mekah dan di sana beliau rajin mengikuti pengajian bandongan di Masjidil Haram.

Sepulangnya ke tanah air Abah Anom harus menghadapi banyak kesulitan, terutama setelah proklamasi kemerdekaan Republik Indonesia 1945. Abah Anom ikut membantu memerangi pemberontakan DI/TII. Sepanjang era 1950-an, pesantren Suryalaya diserang oleh DI/TII sebanyak lebih dari 38 kali. Atas jasa-jasanya Abah Anom mendapat penghargaan dari Kodam VI Siliwangi. Selain itu Abah Anom juga aktif merintis pembangunan di bidang ekonomi dan pertanian di karena pada saat itu kondisi perekonomian sedang sangat memprihatinkan, terutama pada masa pergolakan 1960-an yang berpuncak pada pemberontakan Partai Komunis Indonesia.

Abah Anom menikah dua kali, pertama dengan Hajjah Euis Ru'ayanah ${ }^{2}$, yang wafat pada 1978, dan kemudian menikah lagi dengan Ibu Yoyoh Sofiah ${ }^{3}$. Dalam masalah sosial masyarakat dan kenegaraan beliau senantiasa berpegang pada prinsip Tanbih dan Asas Tujuan TQN yang diwasiatkan oleh ayahandanya.

Dalam praktik ritualnya, Abah Anom terkesan lebih "moderat" dibandingkan beberapa tarekat lain. Misalnya, tidak ada ketentuan hitungan jumlah zikir khafiy, hanya disebut "sebanyak-banyaknya." Tetapi bagi lingkaran ikhwan yang lebih dalam dan serius, Abah Anom memberlakukan aturan yang lebih serius dan ketat, terutama bagi mereka yang benarbenar ingin melakukan suluk.

Karya-karya Abah Anom tentang ibadah Islam pada umumnya dan asas-asas tarekat adalah:

1) Kitab Miftah as-Shudur adalah risalah utama Abah Anom tentang dasar-dasar teoritis dan amalan TQN dalam tradisi Suryalaya, yang aslinya ditulis dalam bahasa Arab, dan telah diterjemahkan ke dalam Bahasa Indonesia (oleh Profesor Abu Bakar Aceh), Inggris dan Melayu.

2) Kitab Uqudul Jum'an adalah keterangan amalan yang dibagi menjadi tiga bagian utama: wiridan, khataman dan silsilah TQN. 
3) Kitab Kurikulum Inabah menjelaskan sistematika pedoman kegiatan ibadah dari sejak bangun tidur hingga tidur kembali.

4) Karya lainnya adalah Akhlaqul karimah/Akhlaqul Mahmudah Berdasarkan Mudaawamah Dzikrillah. ${ }^{4}$

Setelah menjalani masa yang cukup panjang, KH. A Shohibulwafa Tajul Arifin bin Syaikh Abdullah bin Nur Muhammad sebagai Guru Mursyid Tarekat Qodiriyah wa Naqsyabandiyah dengan segala keberhasilan yang dicapainya melalui perjuangan yang tidak ringan, dipanggil Al Khaliq kembali ke Rahmatullah pada hari Senin tanggal 05 September 2011 pukul 11.55 dalam usia 96 tahun.

\section{Strategi Dakwah Abah Anom}

\section{Pengertian Dakwah}

Dakwah secara etimologis adalah bentuk mashdar yaitu kata kerja da'a- yad'uda'watan yang berarti memanggil, mengundang, mengajak, menyeru dan mendorong.

Secara terminologis berarti mengajak dan menyeru umat manusia baik perorangan maupun kelompok kepada agama islam, pedoman hidup yang di ridlai oleh Allah dalam bentuk amar ma'ruf nahi munkar dan amal shaleh dengan cara lisan maupun perbuatan untuk mencapai kebahagiaan hidup di dunia maupun di akhirat nanti. ${ }^{5}$

Dakwah adalah upaya yang dilakukan mukmin untuk mengubah keadaan individu, masyarakat dan kondisi yang atau kurang islami dalam berbagai aspek agar menjadi lebih islami. Setiap muslim mempunyai kewajiban berdakwah, baik secara individu maupun kolektif. Substansi kegiatan dakwah adalah amar makruf nahi mungkar. Sebagai sebuah upaya, dakwah senantiasa berada dalam waktu dan ruang tertentu. Dakwah yang meruang dan mewaktu itu selalu bergumul dengan nilai-nilai, filsafat dan kebudayaan di luar Islam. ${ }^{6}$

Syekh Muhammad al-Khadir Husin menyatakan bahwa dakwah adalah menyeru manusia kepada kebajikan dan petunjuk serta melarang kepada kemungkaran agar mendapat kebahagiaan dunia akhirat. Sejalan dengan itu Toha Abdurrahman menyatakan bahwa dakwah ialah dorongan atau ajakan manusia kepada kebaikan serta melarang kemungkaran untuk meraih kebahagiaan dunia akhirat. Kemudian Abd. Al-Karim Zaidan dengan ringkas menyebut bahwa dakwah adalah mengajak kepada agama Allah, yaitu Islam. ${ }^{7}$

Selain itu M. Quraish Shihab menulis bahwa dakwah adalah seruan atau ajakan kepada keinsafan atau usaha mengubah situasi kepada yang lebih baik dan sempurna terhadap individu dan masyarakat. Perwujudan dakwah bukan sekedar usaha peningkatan pemahaman keagamaan dalam tingkah laku dan pandangan hidup saja, tetapi juga menuju sasaran yang lebih luas. ${ }^{8}$ Asep Muhiddinmenyebut bahwa dakwah adalah upaya kegiatan mengajak atau menyeru umat manusia agar berada di jalan Allah yang sesuai fitrah secara integral. ${ }^{9}$

Sesungguhnya masih banyak definisi tentang dakwah dari para pakar atau ulama yang lain dengan berbagai perspektif. Semua definisi diatas pada intinya menngunkapkan bahwa 
dakwah adalah sebuah kegiatan atau upaya manusia mengajak atau menyeru manusia lain kepada kebaikan. Isi daripada ajakan tersebut adalah al-khayr,amarma'ruf, dan nahi munkar. Hal inilah yang menjadi karakteristik dakwah yang membedakannya dengan kegiatan lain seperti kampanye. Dengan isi ajakan itu dakwah dapat memberikan kontribusi kepada komunikasi manusia dalam wujud etika dan moral. ${ }^{10}$

\section{Pengertian Strategi Dakwah}

Strategi berasal dari bahasa Yunani yaitu "stragos" atau "strategis" dengan kata jamak strategi yang berarti jenderal, tetapi dalam Yunani kuno berarti perwira negara dengan fungsi yang luas. (salulu, 1985: 85). Strategi adalah rencana yang cermat mengenai kegiatan untuk mencapai sasaran khusus. (Depdikbud, 1994: 984). Sedangkan strategi dakwah artinya metode, siasat, taktik atau manuver yang dipergunakan dalam aktifitas (kegiatan) dakwah.

Untuk mencapai keberhasilan dakwah secara maksimal, maka diperlukan berbagai faktor penunjang, di antaranya adalah strategi dakwah yang tepat sehingga dakwah mengena sasaran.

Metode dakwah adalah cara yang digunakan dai untuk mengimplementasi-kan rencana yang sudah disusun dalam bentuk kegiatan nyata dan praktis untuk mencapai tujuan dakwah. Sebenarnya, metode dakwah adalah sesuatu yang lazim dikenal dan diterapkan oleh da'i, akan tetapi secara garis besar dapat dibagi menjadi tiga sebagai berikut;pertama: dakwah bilkitabah yaitu berupa buku, majalah, surat, surat kabar, spanduk, pamflet, lukisan-lukisan dan sebagainya. Kedua: dakwah bil-lisan, meliputi ceramah, seminar, symposium, diskusi, khutbah, saresehan, brain storming, obrolan, dan sebagainya. Ketiga dakwah bil-hal, yaitu berupa prilaku yang sopan sesuai ajaran Islam, memelihara lingkungan, dan lain sebagainya. ${ }^{11}$

Pendekatan dakwah dapat diartikan sebagai titik tolak atau sudut pandang dai terhadap proses dakwah, yang merujuk pada pandangan tentang terjadinya suatu proses yang sifatnya masih sangat umum, di dalamnya mewadahi, menginsiprasi, menguatkan, dan melatari metode dakwah dengan cakupan teoretis tertentu. Terdapat dua jenis pendekatan, yaitu: (1) berorientasi atau berpusat pada $\mathrm{mad}^{\prime} u$, dan (2) berorientasi atau berpusat pada dai.

Selanjutnya metode dakwah dijabarkan ke dalam teknik dakwah. Dengan demikian, teknik dakwah dapat diatikan sebagai cara yang dilakukan seseorang dalam mengimplementasikan suatu metode secara spesifik.

Jadi, pelaksanakan strategi dakwah hendaknya juga memuat metode, pendekatan, dan teknik dakwah agar dakwah bisa tercapai sesuai harapan.

\section{Startegi Dakwah Abah Anom}

Realita yang ada di dalam masyarakat sering terjadi bentuk dakwah yang monoton yang kurang begitu relevan dengan perkembangan zaman dewasa ini. Untuk mengantisipasi trend masyarakat modern harus dapat mempersiapkan materi-materi dakwah yang lebih 
mengarah pada antisipasi kecenderungan-kecenderungan masyarakat. Oleh karena itu, maka seluruh komponen dan segenap aspek yang menentukan atas keberhasilan dakwah harus ditata secara professional dan disesuaikan dengan kondisi mad'u agar dapat menghasilkan kemasan dakwah yang benar-benar mampu memperbaiki dan meningkatkan semangat dan kesadaran yang tulus dalam mengaktualisasikan nilai-nilai ajaran Islam. ${ }^{12}$

Strategi dakwah Abah Anom lebih menekankan pada metode dzikrullah (mengingat Allah). Hal ini didasari firman Allah swt, bahwa Al-Qur'an bisa menjadi obat dan mendatangkan rahmat $^{13}$, menyembuhkan penyakit-penyakit yang ada di dalam dada ${ }^{14}$, dan hati bisa tenteram dengan dzikir. ${ }^{15}$ Juga berdasar Sabda Rasulullah saw, bahwa dzikir adalah obat penyakit hati ${ }^{16}$ dan pencuci hati yang kotor adalah $d z i k r u l l a h^{17}$.

Beberapa strategi dakwah yang digunakan Abah Anom meliputi:

\section{a) Dakwah dengan Tulisan}

Di Pondok Pesantren Suryalaya pada masa periode Abah Sepuh ${ }^{18}$ ajakan dzikrullah disampaikan kepada murid-muridnya melalui metode bil kalam, ceramah, baik di masjidmasjid maupun di rumah-rumah. Oleh karena itu tidak heran bila pada masa ini ajaran dzikrullah tidak banyak ditemukan kecuali sedikit. ${ }^{19}$

Berbeda dengan periode di atas, pada periode Abah Anom ajaran dzikrullah tidak hanya disampaikan dengan metode bil kalam (ceramah) tetapi juga melalui bil kitabah (tulisan). Ajaran dzikrullah dalam bentuk tulisan ini disusun sendiri oleh Abah Anom secara bertahap dan dalam waktu yang cukup lama. Setelah itu diadakan penyempurnaan dan penelaahan kembali yang mendalam sehingga himpunan tulisan ini diberi nama dengan judul Mitahush Shuduur. ${ }^{20}$

Kitab ini, menurut penyusun diperuntukkan bagi murid-muridnya, baik yang berada di dalam maupund i luar negeri. Adapun tujuannya, agar para murid tersebut memperoleh ketegasan dan kemudahan dalam mempelajari serta mengamalkannya, sehingga pada akhirnya diharapkan mereka mendapat ketentraman jiwa dalam hidup di dunia ini dan kemenangan di akhirat. ${ }^{21}$

Kitab Miftahush Shudur ${ }^{22}$ adalah risalah utama Abah Anom tentang dasar-dasar teoritis dan amalan TQN dalam tradisi Suryalaya, yang aslinya ditulis dalam bahasa Arab, dan telah diterjemahkan ke dalam Bahasa Indonesia (oleh Profesor Abu Bakar Aceh), Inggris dan Melayu. Kitab ini terbagi menjadi dua juz (bagian) dengan struktur: (1) pendahuluan, pentingnya zikir secara umum; (2) inti sari konsep nafy wa itsbat dalam zikir; (3) kaifiyyah (tata cara) zikir jahr (dengan suara keras); (4) dasar dan asal-usul talqin (inisiasi atau ba'iat) dan al-ahad (kesetiaan); (5) kewajiban menyebut silsilah tarekat; (6) muqadimmah, ditulis oleh Abu Bakar Aceh; (7) membahas pentingnya ingat kepada Tuhan dan dampaknya bagi pendidikan agama; dan (8) cara melemahkan kekuatan setan dengan amalam zikir.

Kitab Uqudul Jum'an adalah keterangan amalan yang dibagi menjadi tiga bagian utama: wiridan harian, khataman dan silsilah TQN. 
Selain Kitab Miftahush Shuduur dan Uquudul Jum'an, pada tahun 1985 Abah Anom juga membuat buku "Ibadah Sebagai Metoda Pembinaan Korban Penyalahgunaan Narkotika dan Kenakalan Remaja". ${ }^{23}$ Buku ini dijadikan pegangan bagi para pembina $\mathrm{INABAH}^{24}$ khususnya dan bagi murid pada umumnya serta dapat dimanfaatkan demi kemaslahatan umat manusia.

Dalam Kurikulum INABAHini dijelaskan sistematika pedoman kegiatan ibadah dari sejak bangun tidur hingga tidur kembali.INABAHadalah istilah yang berasal dari Bahasa Arab anaba-yunibu (mengembalikan) sehingga inabah berarti pengembalian atau pemulihan, maksudnya proses kembalinya seseorang dari jalan yang menjauhi Allah ke jalan yang mendekat ke Allah. Istilah ini digunakan pula dalam Al-Qur'an yakni dalam Luqman surat ke-31 ayat ke-15, Surat ke-42, Al-Syura ayat ke-10; dan pada surat yang lainnya.

Abah Anom menggunakan nama inabah menjadi metode bagi program rehabilitasi pecandu narkotika, remaja-remaja nakal, dan orang-orang yang mengalami gangguan kejiwaan. Konsep perawatan korban penyalahgunaan obat serta kenakalan remaja adalah mengembalikan orang dari perilaku yang selalu menentang kehendak Allah atau maksiat, kepada perilaku yang sesuai dengan kehendak Allah atau taat.

\section{b) Dakwah dengan Lisan}

Abah Anom dalam setiap bulannya menyelenggarakan pengajian manaqiban, yakni pengajian yang di dalamnya ada pembacaan manaqib/riwayat hidup Syeikh Abdul Qodir Al-Jailany. Di antara rankainnya adalah pembukaan, pembacaan ayat suci Al-Qur'an, pembacaan tanbih Abah Sepuh, ${ }^{25}$ pembacaan tawasul, pembacaan manaqib Syeikh Abdul Qodir Al-Jailany. Di akhir acara diisi dengan pengajian dari para kyai.

Pengajian ini rutin dilakukan dalam setiap bulan sekali. Dalam momentum ini digunakan untuk memberikan pencerahan kepada jamaah. Pengajian ini tidak hanya dikhususkan kepada orang yang telah menjadi murid Abah Anom, melainka juga dibuka umum bagi mereka yang ingin mendalami dan sekedar ingin tahu tentang pelajaran dzikrullah.

\section{c) Dakwah dengan Perbuatan}

Karya lainnya adalah Akhlaqul karimah/Akhlaqul Mahmudah berdasarkan Mudaawamah Dzikrillah. Abah Anom sangat lemah lembut terhadap siapa saja. Akhlak beliau sangat luar biasa. Manifestasi dari ajaran untuk berakhlak mulia diungkapkan dalam Tanbih Abah Sepuh dan untaian mutiara.

Untaian mutiara ${ }^{26}$ disebutkan:

1) Jangan membenci ulama yang sezaman

2) Jangan menyalahkan pengajaran orang lain

3) Jangan memeriksa murid orang lain

4) Jangan berhenti berkarya meskipun disakiti orang

5) Harus menyayangi orang yang membeci kepadamu 
Adapun teknik dakwah yang digunakan Abah Anom adalah dengan melaksanakan amaliah dzikir TQN dari bangun tidur hingga tidur kembali. Yang rangkaiannya.

Teknik dakwah adalah cara yang dilakukan dai dalam rangka mengimplementasikan suatu metode dakwah. Untuk merealisasikan strategi yang telah ditetapkan, kita memerlukan metode. Strategi menunjuk pada sebuah perencanaan untuk mencapai suatu tujuan, sedangkan metode adalah cara yang digunakan untuk melaksanakan strategi. Dalam setiap penerapan metode, dibutuhkan beberapa teknik.

Abah Anom menciptakan metode penyembuhan ini lengkap dengan kurikulum yang sepenuhnya didasarkan atas tradisi sufistiknya. Secara tekniknya, kurikulum inabah dimulai dengan mandi malam atau yang dikenal dengan mandai taubat, kemudian shalat tahajud, tasbih, witir, shalat sunah qabliyah Subuh, sholat sunah li daf'il bala', shalat Subuh, shalat sunah isyraq, shalat sunah isti'adzah, shuha, qabliyah Dhuhur, Dzuhur, qabliyah Asar, qabliyah Maghrib, Maghrib, bakdiyah Maghrib, sunah Awwabin, sunah taubat, sunah birrul walidain, li hifdhil iman, li syukrin ni'mat, qabliyah Isya, Isya, bakdiyah Isya, syukur, sunah muthlaq, istikharah, dan shalat hajat. Setiap selesai shalat mereka berdzikir. ${ }^{27}$

Secara umum, 90 persen kegiatan di inabah berpusat pada shalat, dzikir, dan mandi. Selain melaksanakan perintah agama, mengobati kerinduan jiwa pada sang Pencipta, shalat juga punya efek yaitu menyehatkan tubuh. ${ }^{28}$

Shalat dan dzikir mendominasi kurikulum inabah karena keduanya memiliki daya penyembuh yang luar biasa. Syaikh Hakim Abu Abdullah Ghulam M menulis The book Sufi Healing yang menyebutkan manfaat terapeutik shalat, yang meliputi tiga bidang penyembuhan, ayitu penyembuhan pikiran, ucapan, dan tindakan. ${ }^{29}$

Sedangkan mandi sebelum masuk subuh ternyata memiliki manfaat yang luar biasa bagi kesehatan, baik secara fisik maupun psikis. ${ }^{30}$

Sebelum seseorang melaksanakan dan mengamalkan kurikulum inabah (dzikir), mereka akan ditalqin kalimah tauhid. ${ }^{31}$ Talqin dzikir adalah pembelajaran dzikir pada qalbu (hati). Dzikir tidak cukup diajarkan dengan mulut untuk ditirukan dengan mulut pula, melainkan harus dipancarkan dari qalbu untuk dihunjamkan ke dalam qalbu yang di talqin. Yang dapat melakukan talqin dzikir hanyalah orang-orang yang qalbunya sehat (bersih dari syirik) dan kuat (berisi cahaya ilahi).

Dengan membiasakan dzikir, shalat, dan mandi malam, maka akan datang ketenangan, ketenteraman, dan kebahagiaan ke dalam jiwa. Bahkan penyakit-penyakit kejiwaan lambat laun akan luntur.

Dalam rangka mensukseskan strategi, metode, dan teknik dakwah melalui dzikir ini, Abah Anom menggunakan pendekatan keteladanan. Pendekatan keteladanan mempunyai peranan besar dalam menunjang terwujudnya tujuan dzikrullah dan penyembuhan kejiwaan. Imam Bawani ${ }^{32}$ juga mengatakan bahwa salah satu faktor yang menunjang keberhasilan pembelajaran dalam pesantren adalah terwujudnya keteladanan 
dari seorang kyai. Dalam hal ini bisa dilihat jika ada seorang kyai yang memiliki kepribadian mulia, pasti akan selalu dihargai dan dijadikan panutan oleh lingkungannya.

\section{SIMPULAN}

Permasalahan kehidupan manusia dangat beragam macamnya. Hampir di setiap sudut kehidupan terdapat apa yang dinamakan problematika. Untuk menghadapi dan mencari jalan pemecahan dari berbagai macam persoalan kehidupan yang terjadi, harus memilih dan menggunakan strategi yang tepat sesuai dengan permasalahan yang dihadapi dan sesuai dengan kebutuhan mereka.

Oleh sebab itu, dakwah tidak harus terpaku oleh struktur formal dalam menjalankan tugasnya. Seorang kyai yang berdakwah di lingkungannya biasanya terlahir melalui seleksi alam yang membawanya sebagai dai kharismatik.

Dalam rangka memberikan solusi terhadap berbagai problematika kehidupan, KH. A. Shohibul Wafa Tajul Arifin (Abah Anom) merupakan salah satu tokoh ulama yang sangat diperlukan oleh masyarakat, sebab beliau memiliki komitmen tauhid, istiqamah dan jujur, memiliki visi yang jelas, memiliki wawasan keislaman, memiliki kemampuan memadukan antara dakwah bil-kitabah,dakwah bil-lisan dengan dakwah bil-hal. Kesemuanya itu, beliau rangkum dalam suatu amaliah dzikrullah. Adapun teknik dzikrullah-nya memadukan antara shalat, dzikir dan mandi taubat. Dalam dakwahnya, Abah Anom menggunakan pendekatan keteladanan sebagai uswah bagi anak muridnya dan orang lain.

\footnotetext{
${ }^{1}$ Abah Anom adalah pemimpin pesantren Tarekat Qadiriyyah wa Naqsyabandiyyah (TQN) terbesar di Indonesia, yakni Pondok Pesantren Suryalaya di Tasikmalaya, Jawa Barat. beliau dikenal sebagai "Abah Anom" atau "Kyai Muda", karena beliau diangkat menggantikan ayahnya sebagai pemimpin pesantren dalam usia masih muda, yakni 35 tahun.

${ }^{2}$ Dari istri pertamanya beliau dikaruniai 13 putera dan putri; Dudun Nursaidudin, Aos Husni Falah, Nonong, Didin Hidir Arifin, Noneng Hesyati, Endang Ja'far Sidiq, Otin Khadijah, Kankan Zulkarnaen, Memen Ruhimat, Ati Unsuryati, Ane Utia Rohyane, Babn Ahmad Jihad, dan Nur Iryanti.

${ }^{3}$ Dari istri keduanya beliau dikaruniai anak lelaki yang diberi nama Ahmad Masykur Firdaus.

4 Harun Nasution, dkk., Thoriqot Qodiriyyah Naqsyabandiyyah: Sejarah Asal-Usul, dan Perkembangannya, (Tasikmalaya: IAILM, 1990), hlm. 111-198.

${ }^{5}$ Siti Muri'ah, Metode Dakwah Kontemporer, (Yogyakarta: Mitra Pustaka, 2000), hlm. 2-3.

${ }^{6}$ Nawari Ismail, Pergumulan Dakwah Islam dalam Konteks Sosial Budaya: Analisis Kasus Dakwah, (Yogyakarta: Pustaka Pelajar, 2010), hlm. 119.

${ }^{7}$ Moh Ali Aziz, Ilmu Dakwah, (Jakarta: Prenada Media Group, 2009), hlm. 13.

${ }^{8}$ Anwar Arifin, Dakwah Kontemporer: Sebuah Studi Komunikasi, (Yogyakarta: Graha Ilmu, 2011), hlm. 36.

${ }^{9}$ Asep Muhidin, Metode Pengembangan Dakwah, (Bandung: Pustaka Setia, 2002), hlm. 19.

${ }^{10}$ Ibid.

${ }^{11}$ Ibid.

${ }^{12}$ Ahmad Anas, Paradigma Dakwah Kontemporer, (Semarang: Pustaka Rizki Putra, 2005), hlm. 110.
} 
13 QS. Al-Isra': 82. Artinya: “Dan kami turunkan dari Al-Qur'an suatu yang menjadi penawar dan rahmat bagi orang-orang yang beriman dan Al-Qur'an itu tidaklah menambah kepada orang-orang yang dzalim selain kerugian."

${ }^{14}$ QS. Yunus: 57. Artinya: "Hai manusia sesungguhnya telah datang kepadamu pelajaran dari Tuhanmu dan jadi penyembuh bagi penyakit-penyakit (yang berada) dalam dada dan petunjuk serta rahmat bagi orangorang yang beriman."

15 QS. Ar-Ra'du: 28. Artinya: "Yaitu orang-orang yang beriman dan hati mereka menjadi tenteram dengan mengingat Allah, perhatikanlah hanya dengan mengingat Allah itu hati menjadi tenteram."

16 "Ingat kepada Allah itu menjadi obat yang mustajab, guna menyembuhkan segala penyakit hati. "

17 "Sesungguhnya untuk segala perkara itu ada obat pencucinya, sedangkan pencuci hati itu adalah dzikir (ingat hati) kepada Allah”

${ }^{18}$ Abah Sepuh bernama asli KH. Syeikh Abdullah Mubarok bin Nur Muhammad. Beliau adalah ayahanda Abah Anom.

${ }^{19}$ Harun Nasution, Op. Cit., hlm. 257.

${ }^{20}$ Ibid.

${ }^{21}$ Prakata KH. A. Shohibul Wafa Tajul Arifin, Miftahush Shuduur (Terjemahan Prof. K.H. Aboebakar Atjeh), Jilid I, Kutumas, Sukabumi, 1970, hlm. 3.

${ }^{22}$ A. Shohibul Wafa Tajul Arifin, Miftahush Shuduur, (Tasikmalaya: PP. Suryalaya, 1990), hlm. 1-63.

${ }^{23}$ Harun Nasution, Op. Cit., hlm. 393.

24 INABAH adalah sebuah "Panti Asuh" yang dikhususkan bagi mereka yang menderita gangguan kejiwaan, penyalahgunaan narkotika, zat adiktif lain dan kenakalan remaja.

${ }^{25}$ Abah Sepuh bernama asli Syeikh Abdullah Mubarok bin Nur Muhammad. Beliau adalah ayahanda Abah Anom.

${ }^{26}$ Harun Nasution, Op. Cit., hlm. 254.

${ }^{27}$ Harun Nasution, Op. Cit., hlm. 397-410. Lihat juga Asep Salahudin, Pangersa Abah Anom: Wali Fenomenal Abad 21 \& Ajarannya, (Jakarta: Noura Books, 2013), hlm. 58.

${ }^{28}$ Seorang pakar ilmu pengobatan tradisional, Prof H Muhammad Hembing Wijayakusuma, telah melakukan penelitian yang mendalam tentang hal itu. Hasil penelitian itu disebarkannya kepada umat Islam, baik melalui media massa maupun buku yang berjudul "Hikmah Sholat untuk Pengobatan dan Kesehatan". Bahkan, duduk Tasyahud diyakini bisa menyembuhkan penyakit tanpa operasi. Menurut Hembing, setiap gerakangerakan shalat mempunyai arti khusus bagi kesehatan dan punya pengaruh pada bagian-bagian tubuh seperti kaki, ruas tulang punggung, otak, lambung, rongga dada, pangkal paha, leher, dan lain sebagainya.

${ }^{29}$ Asep Salahudin.Loc. Cit.

${ }^{30}$ Menurut Dr. dr. Aru W. Sudoyo, MD dokter spesialis penyakit dalam dari FK UI dan RS Medistra, mandi pagi secara medis akan merangsang sistem peredaran darah dan persyarafan menjadi lebih aktif. Hal ini timbul sebagai reaksi terhadap rangsangan suhu dingin secara singkat. Sepanjang seseorang tidak sakit, maka mandi subuh atau sebelum subuh memberikan efek positif karena tubuh dicambuk oleh temperature rendah.dr. Midi Hariyani, SpKK spesialis kulit dan kelamin dari klinik nusantara kuningan menyebutkan bahwa dengan mandi subuh dapat membangunkan tubuh yang terlelap dimana metabolisme tubuh sedang melambat.Diibaratkan membangunkan mesin yang awalnya pelan kemudian dinaikkan. Suhu tubuh akan dinaikkan mencapai kestabilan. Jantung menjadi terpacu untuk bangun,adrenalin meningkat, pembuluh darah jadi lebih lancar untuk bergerak sehingga aliran darah dalam tubuh menjadi sangat baik termasuk aliran ke kulit. Sehingga kulit tampak lebih fresh. Lihat http://www.newselvi.com/2014/07/waktu-mandi-yangmenyehatkan.html. Diakses pada Sabtu, 14 Mei 2016.

${ }^{31}$ Kalimah laailaaha illallah dan Allahu Allah.

${ }^{32}$ Armai Arief, Pengantar Ilmu dan Metodologi Pendidikan Islam, (Jakarta: Ciputat Pers, 2002), hlm. 120. 


\section{DAFTAR PUSTAKA}

A. Shohibul Wafa Tajul Arifin. 1990.Miftahush Shuduur, Tasikmalaya: PP. Suryalaya. Ahmad Anas. 2005. Paradigma Dakwah Kontemporer, Semarang: Pustaka Rizki Putra..

Anwar Arifin. 2011. Dakwah Kontemporer: Sebuah Studi Komunikasi, Yogyakarta: Graha Ilmu.

Armai Arief. 2002. Pengantar Ilmu dan Metodologi Pendidikan Islam, Jakarta: Ciputat Pers.

Asep Muhidin. 2002. Metode Pengembangan Dakwah, Bandung: Pustaka Setia.

Asep Salahudin. 2013. Pangersa Abah Anom: Wali Fenomenal Abad 21 \& Ajarannya, Jakarta: Noura Books.

Harun Nasution, dkk.. 1990. Thoriqot Qodiriyyah Naqsyabandiyyah: Sejarah Asal-Usul, dan Perkembangannya, Tasikmalaya: IAILM.

Moh Ali Aziz. 2009.Ilmu Dakwah, Jakarta: Prenada Media Group.

Nawari Ismail. 2010. Pergumulan Dakwah Islam dalam Konteks Sosial Budaya: Analisis Kasus Dakwah, Yogyakarta: Pustaka Pelajar.

Siti Muri'ah. 2000. Metode Dakwah Kontemporer, Yogyakarta: Mitra Pustaka.

http://www.newselvi.com/2014/07/waktu-mandi-yang-menyehatkan.html. 